\title{
Social and Economic Determinants of Kaluga Region Population Poverty
}

\author{
V.N. Kruglov, D.V. Tyutin, and N.V. Kharchikova
}

The Russian Presidential Academy of National Economy and Public Administration, Kaluga branch, city of Kaluga, Russian Federation

\begin{abstract}
The article analyzes the spatial disproportions of the municipalities of Kaluga region from the point of view of social and economic development and impact on population poverty. Subsequently, the estimates obtained were compared with the results of a sociological survey of region residents in terms of assessing the spatial dispersion of poverty and government policy measures. The concentration of poverty within the region makes it possible to identify the economic prerequisites for poverty associated with the heterogeneous development of territories and municipalities. The existing differentiation is based on differences in the level of production, resource, infrastructural, demographic and other development of municipalities, forming specific poverty lines. On the basis of obtained comparisons, conclusions are drawn about the need to develop specific measures of the regional policy aimed at improving the population quality of life due to the formation of dynamic competitive economic complex and high business activity in the region.
\end{abstract}

\section{Introduction}

The Order of the President of the Russian Federation dated May 7, 2018 No. 204 "On National Goals and Strategic Objectives of the Russian Federation Development through to 2024" [1] establishes National Development Goals among which was declared the twofold poverty decrease.

The key imperative of the state regional policy aimed at reducing population poverty is to increase targeted support for the poor. In this regard, the issues of quantitative and qualitative assessment of poverty become relevant, since a set of specific selective regional policy measures that ensure a certain level of material well-being of households will depend on its results.

\section{Materials and Methods}

Within the study is conducted the multidimensional classification of municipalities in Kaluga region on the basis of municipal statistics indicators, to one degree or another characterizing 
the state of the problem of poverty and the prerequisites for its formation. Further, the results of the "statistical" assessment were compared with the results of a sociological survey of residents of the region. The main method of sociological research is an anonymous survey of respondents. The respondents were asked to answer the questionnaire questions without the participation of the research performers. In the process of collecting the questionnaires, the respondents had the opportunity to express their own opinions and attitudes towards the goal and expected results of the study. The sample of respondents was carried out at random and amounted to 1023 people.

The research methodology is based on the traditional concept of sociological research, which proceeds from the assumption of complete coincidence of the cognitive task of the question, its wording, the respondent's perception of the meaning of the question, his desire and ability to give a reliable answer. This technique involves personal individual questioning of respondents in writing, followed by qualitative and quantitative processing of information. The study used a handout questionnaire, during which the questionnaire is left to the respondent to fill out, and then collected at the agreed time.

According to the degree of questioner participation in the study, two types of research were used:

1) in the presence of the questioner, when he instructs the respondent before the start of the survey and helps him, if necessary, directly during the survey;

2 ) in the absence of the questionnaire, when contact with the respondent is limited to an introductory briefing when the questionnaire is handed over to him and a control review when it is returned.

The direct assessment of poverty and the underlying methodological approaches continue to be a debatable topic, both theoretical and practical, since it is based on two components: objective and subjective. The objective side of the assessment can be considered the use of available statistical indicators characterizing the level of material well-being (income, consumption) and its non-monetary aspect, which can be represented by the availability of social services in the form of health care, education, culture, social support and services. At the same time, these characteristics can be assessed by individuals (households) and subjectively, based on their own perception of their social, economic situation, existing structures of everyday life. In this regard, the task of forming a methodological basis for assessing poverty of the population at the regional level is reduced to the determination of objective determinants that determine the current level of the material situation of households.

The economic theory of welfare contains two approaches to measuring poverty - based on household income and their expenditures. In the studies by Paul Anthony Samuelson and John Richard Hicks, income is recognized as income that has a regular basis and does not arise from the disposal of household property. E. Engel (Ernst Engel), R. Haig (Robert M. Haig) consider income as the sum of household expenditures on consumption, as well as the change in the value of their property.

In 1990, the World Bank prepared a global assessment of poverty in developing countries for the World Development Report, and, starting with this report, proposed a single standard - a single line of absolute poverty. "According to the method proposed by the World Bank, the international poverty line is correlated with the level of per capita income or per capita consumption, which includes an estimate of income in kind and the cost of consumption of products of our own production" [2].

The UN Economic and Social Council in 1984 defined: "The poor include individuals, families, groups of people whose resources are so limited that they do not allow them to lead a minimum acceptable lifestyle in the states in which they live" [3].

In 2003, during the 17th International Conference of Labor Statisticians, an income-based approach to the definition of poverty was postulated. The resolution on statistics of household 
income and expenditure notes: "Household income includes all cash or in-kind receipts (goods and services) that this household or its individual members receive on an annual or more frequent basis, excluding sudden earnings and other similar irregular and usually onetime receipts. Household income is available for current consumption and does not reduce the household's own capital by reducing its cash, spending other financial and non-financial assets or increasing its liabilities" [4].

In the presented logic, there are three main approaches to assessing poverty of the population.

1. The assessment of absolute poverty is based on comparing the current level of household income and the number of resources required to meet basic needs, taking into account the household size. Absolute poverty determines the value of the minimum income value at which an individual has the means to maintain life at a physiological level.

The use of the criterion of absolute poverty to classify a certain part of the households as poor assumes the establishment of an appropriate boundary - a certain level of income, reflecting the boundary of absolute poverty. The fact that a household receives a per capita income below the absolute poverty indicator indicates that individuals do not have the minimum amount of money necessary for physical existence. This indicator can be used to determine selective government policy measures.

2. The relative assessment of poverty is based on the comparative characteristics of the material security of the household (its individuals) and the level of well-being of the population in a particular place of residence. This approach was proposed by $P$. Townsend, who used the concept of deprivation (from the Latin deprivativo - deprivation) in his studies of poverty [6]. Deprivation is considered as a social process of reduction or complete deprivation of an individual (household) of the opportunity to satisfy vital needs.

The logic of assessing relative poverty is based on the ratio of individual indicators of well-being with the level of material security prevailing in a particular area. Relative poverty is determined by the lack of opportunities to lead the way of life that is customary for the overwhelming majority of members of the local community. At the same time, the multidimensional deprivation underlying the assessment of relative poverty reflects the composition of restrictions and / or deprivations that an individual (household) experience.

In addition to material deprivation, an assessment of social deprivation is used, considering the possibility to obtain health care services, education, leisure, etc.

The relatively poor do not have a level of consumption that is available to the bulk of residents in a particular territory, as a result of which they experience a sense of social exclusion (exclusion), inaccessibility of the standard of living prevailing in the place of residence.

Absolute poverty can be leveled by social policy measures aimed at supporting the poor and ensuring a standard of consumption. Relative poverty as a phenomenon is not subject to smoothing, since with the so called human capital, the differentiation of income and the level of well-being is socially dependant, determined by the difference in the level of motivation, the ability to learn and the formation of soft skills and hard skills throughout life, the level of material well-being achieved by previous generations of the family.

3. The subjective assessment of poverty is based on the opinion of an individual (household members) about the level of financial situation and quality of life. The subjective approach is based on ideas about how much resources a household needs to meet basic needs: the ability to pay for food, buy clothes, shoes, purchase durable goods, furniture, housing, etc.

The analysis of quantitative and qualitative parameters of poverty makes it possible to obtain a comprehensive assessment of the factors (determinants) of the emergence of multidimensional deprivation as a phenomenon of social, economic, and demographic nature. In addition, the analysis of the reasons for the poverty of the population of the region should 
take into account the intra-regional spatial specifics, determine the "general and specific" in the determinants of poverty of the population of certain intra-regional territories.

For the purposes of this study, we used quantitative and qualitative methods for analyzing the poverty of the population of Kaluga region. Among the quantitative characteristics of the poverty level, we used criteria that reflect the scale of poverty, its spatial concentration and distribution over the region.

The analysis of the spatial distribution (dispersion) of poverty or, on the contrary, its concentration (focal character) within the region allows to identify the economic prerequisites for poverty associated with the heterogeneity of development of territories and municipalities. The existing differentiation is based on differences in the level of production, resource, infrastructural, demographic and other development of municipalities, which forms specific lines of poverty within the territories. In this aspect, the problem of poverty must be considered from the standpoint of the spatial development of territories within the region [7].

The quantitative criteria in assessing poverty are indicators of the numerical and age composition of households, assessing the impact of the demographic burden on the level of their material well-being.

The quantitative assessment of poverty is demonstrated by indicators of its scale in gender and age aspects. Gender characteristics of poverty are determined by the "roles of the sexes" and the encouragement of certain socio-economic behavior in society, forming a kind of patriarchal and prerequisites for self-reproducing poverty. At the same time, the age analysis of poverty gives an idea of prospects of this phenomenon: the presence (or, even worse, the predominance) of young people in the structure of the poor indicates the chronic nature of the phenomenon.

In the context of the gender and age aspects of poverty, which determine the conditions for its self-reproduction, as a quantitative criterion for analyzing this phenomenon, one can use the indicator of the duration of poverty - the period of time during which a household (an individual) was in a state of multidimensional deprivation. Thus, an important quantitative characteristic is the indicator of the duration of residence of households and individuals in a state of poverty, which determines its reproducibility.

The qualitative indicator reflecting the likelihood and scale of self-reproducing (chronic) poverty is the indicator of the level of education. The presence of education or the willingness to receive it from persons who find themselves in a difficult material situation indirectly indicates the internal mobilization resources of a person, which can be used to solve the problem due to a change in profession, place of residence. Whereas the insufficient level of education against the background of multidimensional deprivation "conserves" and reproduces the factors of poverty, depriving the individual of opportunities for labor and social mobility.

\section{Results and discussion}

The assessment of poverty differentiation by municipalities of Kaluga region makes it possible to determine the territorial projection of poverty on the map of the region (identification of urban and rural poverty). The figure shows the distribution of municipalities in the region by statistical indicators characterizing the level of well-being. 


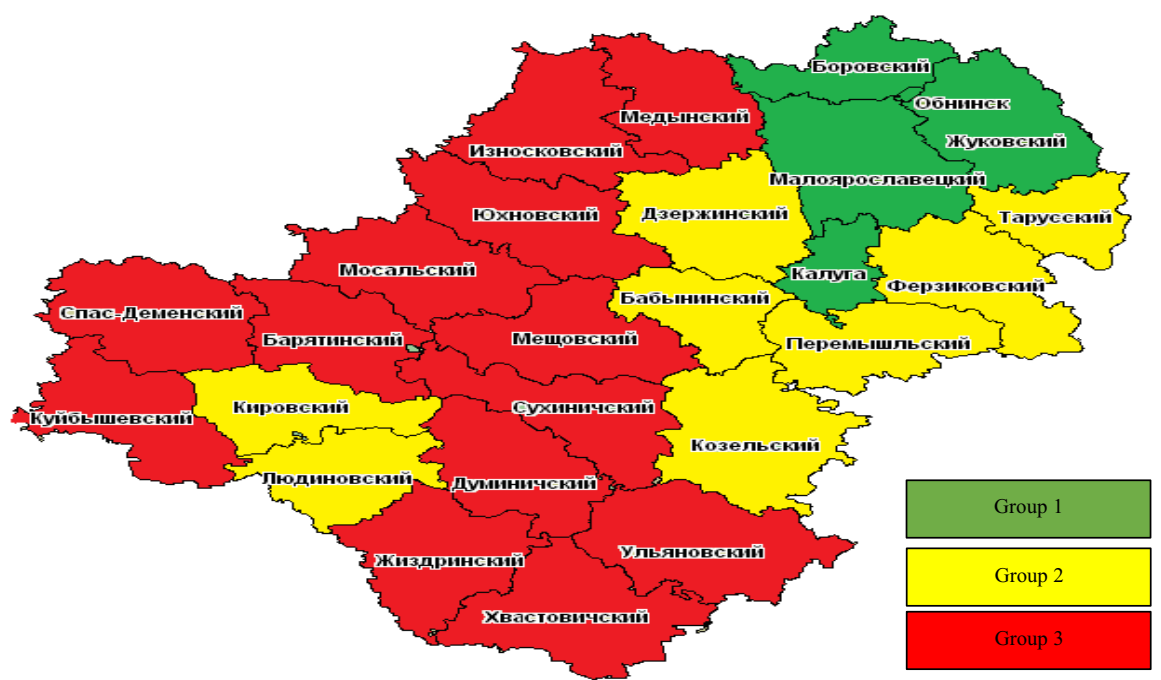

Fig. 1. Distribution of Kaluga region municipalities by the value of the average monthly nominal accrued wage.

Where: Износковский - Iznoskovsky district; Медынский - Medynsky district; Боровский - Borovsky district; Обнинск-Obninsk; Жуковский-Zhukovsky district; Малоярославецкий-Maloyaroslavetsky district; ТарусскийTarussky district; Калуга-Kaluga; Ферзиковский-Ferzikovsky district; Перемышльский-Peremyshlsky district; Козельский-Kozelsky district; Ульяновский-Ulyanovsky district; Хвастовичский-Khvastovichsky district; Жиздринский-Zhyzdrinsky district; Думиничский - Duminichesky district; Сухиничский - Sukhinichsky district; Мещовский - Meschovsky district; Бабынинский - Babyninsky district; Дзержинский - Dzerzhinsky district; Юхновский - Yukhnovsky district; Мосальский - Mosalsky district; Барятинский - Baryatinsky district; Кировский - Kirovsky district; Людиновский - Lyudinovsky district; Куйбышевский - Kuybyshevsky district; Спас-Деменский - Spas-Demensky district

The first ("green") group includes municipalities, the range of the average monthly nominal accrued wages of which is from 38 to 47.5 thousand rubles. The second ("yellow") group of municipal districts has a value of the average monthly nominal accrued wages from 29 to 38 thousand rubles. The third ("red") group of municipalities is characterized by the range of the average monthly nominal accrued wages from 20 to 29 thousand rubles.

Comparison of the results of the sociological survey with the data of official statistics allows us to note the closeness of the estimates and indicates the presence of a representative sample of the respondents. However, it seems appropriate for the detailed comparison of assessment results:

1. The composition of the first ("green") group of municipalities in the two variants of the grouping remained unchanged, which allows us to state for these municipalities the absence of the acuteness of the problem of poverty, its systemic causes.

2. The composition of the second ("yellow") group is identical, but it varies significantly. The results obtained in the course of the sociological study look more optimistic than the results of grouping based on statistical data on the indicator of nominal accrued wages. Comparison of the results of the grouping shows that the composition of the "yellow" group, formed in the course of the sociological survey, is much wider due to the inclusion of municipalities in it, which in the "salary" group were in the "red" group. These are Medynsky, Yukhnovsky, Mosalsky, Baryatinsky, Meschovsky, Sukhinichsky, Zhizdrinsky municipalities. It can be assumed that the respondents' perception of the problem of poverty in these territories is less acute due to the fact that the main activity in the economy of these municipalities is agriculture, and part of the income of households in these territories is formed in personal farmsteads. 
Municipalities of the region in terms of the population's perception level of poverty issue are quite strongly differentiated. Municipalities with the highest incomes of the population: the urban districts of Kaluga and Obninsk, as well as municipal districts that fall within the zone of action of the Moscow agglomeration (Borovsky, Zhukovsky, Maloyaroslavetsky) can be classified as safe by regional standards. These municipalities are characterized by high investment dynamics, the growth of new industries, the creation of jobs with a high share of added value.

The second group of municipal districts is relatively prosperous territories, the economy of which is characterized by the types of activities traditional for Kaluga Region (manufacturing, agriculture), but with lower investment dynamics. The level of wages in these municipalities is lower than in the previous group. It is permissible to assume that part of the income of the population in these territories is formed in the personal subsidiary plots of citizens.

The third group of municipalities is characterized by the lowest values of the average monthly nominal accrued wages, as well as low sociological estimates of household income. In the overwhelming majority, these are agricultural territories with a high level of employment of the population in personal subsidiary plots and a limited number of highly productive jobs.

The results of the gender and age analysis of poverty make it possible to note among the households of Kaluga Region the presence of a sufficiently high gender and age neutrality in relation to poverty problems.

Provided that the obtained results make it possible to state the presence of a stable state of poverty for the significant part of respondents. This happens without a clearly expressed gender tendency in assessments, for example:

- $80 \%$ of respondents (both men and women) do not note the positive dynamics of the material well-being of their families;

- more than $58 \%$ of respondents in each gender group indicated that they felt poor for 3 5 years.

In terms of age, there are also no specific population groups characterized by the presence of factors that determine the state of poverty. Separately, one can point to the presence of overestimated expectations and, as a result, not fully justified estimates of poverty by the youngest audience of respondents (18-20 years old). Provided that the analysis showed that the trend of income formation in the age groups of 18-20 and 20-30 years old has a positive trend.

People of different ages are at risk of poverty in Kaluga Region. From the point of average size per capita family income, the age group of respondents over 60 has more than $19.7 \%$ of families receiving income per family member less than 10 thousand rubles, which allows us to state that there is a threat of poverty for older people.

The assessment of respondents' education level and the dynamics of their material wellbeing (poverty) shows the presence of stable links between these two parameters.

The distribution of respondents with different levels of education in groups characterized by the size of the average per capita family income shows fairly similar results. That is, regardless of the level of education, the percentage of families with low, medium and high per capita incomes is approximately the same. This means that the economy of Kaluga Region has created equal employment opportunities and income generation for people with different levels of education.

Moreover, it can be stated that having a higher education is not a sign of high-income families. Nevertheless, the study results show that specialists with higher education have the best indicators in the dynamics of changes in the material well-being of families. Thus, it can be stated that having a higher education provides the best material results for a family. 
The indicator of the percentage of families who have improved their financial situation allows us to note that the most prosperous are respondents with secondary vocational and primary vocational education. The development of new production facilities in Kaluga Region provided employment opportunities and increased material well-being for employees with specialized vocational education.

Based on the data obtained, the presence of a stable relationship between the level of education and the state of material well-being of the family can be stated. The risk group, from among the possible applicants to fall below the poverty line, is likely to be formed in the future by persons with secondary general and basic general education.

The impact assessment of the number and age composition of households, the demographic load on the level of their material well-being shows that the size of the family has a direct impact on the level of material well-being. In Kaluga Region, numerous families (consisting of 5 and 6 people) with low average per capita incomes have a greater share in comparison with other families, thus, it is for this category of families that the risks of poverty are highest.

The demographic load of households has a significant impact on the level of their material well-being. A certain part of this burden is formed by persons of retirement age. The study showed that 39 percent of the retirees who took part in the survey continue to work. However, the percentage of working pensioners receiving an income of less than 10 thousand per month is twice as high as for households in Kaluga region.

Within 3-5 years, 59\% of the respondents felt themselves poor many times. Episodic situations in which an individual faced the problem of a lack of money and (or) material resources in a particular situation, which do not have a long duration in time or regular recurrence, are in fact not cases of poverty and, most likely, can be attributed to formal poverty. $73 \%$ of the respondents were in a prolonged state of poverty. This indicator cannot be considered insignificant, at the same time it should be noted that a fairly significant part of the respondents mentally classifies themselves as poor, but in fact, they are not.

About $70 \%$ of respondents indicate external circumstances as reasons for low family income, which is a reflection of a high level of social apathy, the unwillingness of a significant part of the population to change. Such results allow one to state the social and economic passivity of a significant part of the population, high risks of poverty.

$5 \%$ of the respondents indicate low interest in work and personal development as the cause of poverty, which is also a manifestation of social apathy. To overcome such negative social sentiments, measures of regional information policy, thematic propaganda campaigns aimed at informing citizens about the available opportunities for prospective education and employment are needed.

$8 \%$ of respondents indicate reasons for poverty in the absence or insufficient qualifications, and another $20 \%$ pointed to the underdevelopment of local labor markets. It requires regional policy measures to diversify the municipal economy, implement professional retraining and advanced training programs in accordance with the future needs of local industries.

The overwhelming majority of the surveyed (91\%) respondents are not familiar with the measures of state and regional support for low-income citizens and the directions of state and regional policies to reduce poverty.

Respondents rate the efficiency of social support measures rather low: $89 \%$ of respondents answered that the available types of government assistance do not affect welfare in any way.

Over the past $3-5$ years, $69 \%$ of respondents felt poor, while only $9 \%$ of respondents are familiar with measures to support people in difficult economic situations. Based on the high diametric nature of the estimates obtained, we can conclude that the mental value judgment "I am poor" prevails among a part of the population. 
Provided that the actual financial situation is not critical, the individual does not take significant efforts to change the financial situation and does not even try to solve the problem with the help of the state. In the result: the low percentage of those who are aware of government support measures.

It is possible that a part of the population in a difficult financial situation does not have the necessary level of awareness about measures of state and regional support for low-income citizens due to limited education, lifestyle and other subjective factors. In this situation, the role of structural units of social protection in municipal administrations, as well as non-profit and public organizations, increases.

The respondents' assessment of their readiness to implement measures to overcome the crisis has many answer options. 35\% of respondents believe that they have good opportunities and resources to get out of poverty or avoid it. $24 \%$ of respondents are dominated by "dependent" sentiments associated with the expectation of growth in payments from the state, and $41 \%$ of respondents believe that the current situation cannot be changed. Thus, the percentage of negative sentiments of the respondents is $65 \%$, which once again confirms the presence of social apathy in a certain part of the audience.

The mentioned trend is clearly negative. The modern context requires the development of social policy accompanied by a reorientation of the pension system and the social security system to stimulate the production activity of the population. At the same time, the actual behavior of a significant part of the respondents is associated with overestimated expectations and requirements in relation to the state, or an obvious unwillingness to make efforts to get out of the crisis, motivated by the statement "This situation cannot be changed".

\section{Conclusions}

Thus, in the course of the analysis of the spatial experience of poverty reduction, differences in measures of its prevention and reduction were revealed. Poverty appears to be a global issue that can be solved. This is confirmed by the high living standards achieved by a group of leading European countries with a low proportion of poor citizens. It is obvious that the joint efforts of all mankind are needed to eliminate this problem.

At the level of the Russian Federation, in this regard, the implementation of innovation policy by regions is important. The measures developed on its basis will help overcome negative and consolidate positive trends in the development of the real sector of the economy, continue economic growth, improve the financial condition of enterprises, maintain human resources, and, therefore, significantly improve the quality of life of the entire population.

At the same time, the main results will be the formation of a favorable investment and business climate, an increase in the inflow of investments into the region; improving the quality of life of the population of individual territories due to the formation of a dynamic competitive economic complex and high business activity in the region; creation of economic conditions conducive to effective employment of the population and allowing the able-bodied population to provide a decent standard of living at the expense of their own income.

\section{References}

1. The Order of the President of the Russian Federation dated May 7, 2018 No. 204 (in force as of 19.07.2018) "On National Goals and Strategic Objectives of the Russian Federation Development through to 2024", http://www.consultant.ru/

2. Methodologic practice of the Eurasian economic union member states on the formation of parameters characterizing poverty. December 27, 2019, http://www.eurasiancommission.org/ 
3. D. Ramprakash, Statistical study of poverty, Report on household statistics meeting. Geneva, March 14-17 (1994)

4. The $17^{\text {th }}$ ILO International conference of labour statisticians. Geneva, November 24 December 3, 2003. Report II. Household income and expenditure statistics, https://www.ilo.org/

5. V.N. Kruglov, E.N. Gerasikova, T.V. Lesina, O.S. Shaurina, N.V. Maslennikova, T.G. Aygumov, Revista inclusiones, 7, 159(2020)

6. P. Townsend, British journal of sociology (1954)

7. D. Tyutin, E. Emelyanova, T. Lesina, N. Kharchikova, N. Maslennikova, T. Aygumov, Amazonia Investiga, 8(21), 551 (2019).

8. D.V. Tyutin, A.V. Gorbatov, A.O. Gomaleev, N.V. Maslennikova, L.K. Ulibina, International journal of engineering and advanced technology, 5, 2064(2019) 